\title{
Airbreathing Hypersonic Vision-Operational-Vehicles Design Matrix
}

James L. Hunt

NASA Langley Research Center, Hampton, VA

Robert J. Pegg

and

Dennis H. Petley

NASA Langley Research Center, Hampton, VA

1999 World Aviation Conference

October 19-21, 1999

San Francisco, CA

\section{DTe Engineering Society - F For Advancing Mobility \\ L Land Sea Air and Space}

SAE International

400 Commonwealth Drive

Warrendale, PA 15096-0001 U.S.A.

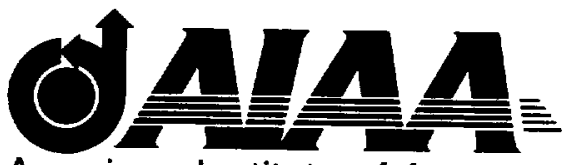

American Institute of Aeronautics and Astronautics

370 L'Enfant Promenade, S.W.

Washington, D.C. 20024

For permission to copy or republish, contact the American Institute of Aeronautics and Astronautics or SAE International. 
Published by the American Institute of Aeronautics and Astronautics (AIAA) at 1801 Alexander Bell Drive, Suite 500, Reston, VA 22091 U.S.A., and the Society of Automotive Engineers (SAE) at 400 Commonwealth Drive, Warrendale, PA 15096 U.S.A.

Produced in the U.S.A. Non-U.S. purchasers are responsible for payment of any taxes required by their governments.

Reproduction of copies beyond that permitted by Sections 107 and 108 of the U.S. Copyright Law without the permission of the copyright owner is unlawful. The appearance of the ISSN code at the bottom of this page indicates SAE's and AIAA's consent that copies of the paper may be made for personal or internal use of specific clients, on condition that the copier pay the per-copy fee through the Copyright Clearance Center, Inc., 222 Rosewood Drive, Danvers, MA 01923. This consent does not extend to other kinds of copying such as copying for general distribution, advertising or promotional purposes, creating new collective works, or for resale. Permission requests for these kinds of copying should be addressed to AIAA Aeroplus Access, 4th Floor, 85 John Street, New York, NY 10038 or to the SAE Publications Group, 400 Commonwealth Drive, Warrendale, PA 15096. Users should reference the title of this conference when reporting copying to the Copyright Clearance Center.

ISSN \#0148-7191

This paper is declared a work of the U.S. Government and is not subject to copyright protection in the United States.

All AIAA papers are abstracted and indexed in International Aerospace Abstracts and Aerospace Database.

All SAE papers, standards and selected books are abstracted and indexed in the Global Mobility Database.

Copies of this paper may be purchased from:

AIAA's document delivery service

Aeroplus Dispatch

1722 Gilbreth Road

Burlingame, California 94010-1305

Phone: (800) 662-2376 or (415) 259-6011

Fax: (415) 259-6047

or from:

SAExpress Global Document Service

c/o SAE Customer Sales and Satisfaction

400 Commonwealth Drive

Warrendale, PA 15096

Phone: (724) $776-4970$

Fax: (724) $776-0790$

SAE routinely stocks printed papers for a period of three years following date of publication. Quantity reprint rates are available.

No part of this publication may be reproduced in any form, in an electronic retrieval system or otherwise, without the prior written permission of the publishers.

Positions and opinions advanced in this paper are those of the author(s) and not necessarily those of SAE or AIAA. The author is solely responsible for the content of the paper. A process is available by which discussions will be printed with the paper if it is published in SAE Transactions. 


\title{
Airbreathing Hypersonic Vision-Operational-Vehicles Design Matrix
}

\author{
James L. Hunt \\ Robert J. Pegg \\ Dennis H. Petley \\ NASA Langley Research Center, \\ Hampton, VA
}

\begin{abstract}
This paper presents the status of the airbreathing hypersonic airplane and space-access vision-operational-vehicle design matrix, with emphasis on horizontal takeoff and landing systems being studied at Langley; it reflects the synergies and issues, and indicates the thrust of the effort to resolve the design matrix including Mach 5 to 10 airplanes with global-reach potential, pop-up and dual-role transatmospheric vehicles and airbreathing launch systems. The convergence of several critical systems/technologies across the vehicle matrix is indicated. This is particularly true for the low speed propulsion system for large unassisted horizontal takeoff vehicles which favor turbines and/or perhaps pulse detonation engines that do not require LOX which imposes loading concerns and mission flexibility restraints.
\end{abstract}

\section{INTRODUCTION}

Airbreathing hypersonic vehicles encompass cruise airplanes with speeds from Mach 5 to 12, and space access vehicles that accelerate from takeoff to orbital speeds. (Missiles are a part of the matrix but will not be included in this paper.) The cruiser designs reflect high lift-to-drag whereas the accelerators reflect low drag per unit inlet capture; thus, these engine/airframe integrated designs that are prescribed for acceleration missions attribute a much larger percentage of their fuselage cross section to the propulsion flow path.

One of the more design influencing items is fuel. The hydrogen-fueled vehicles must be very volumetrically efficient to contain the low density fuel and thus tend to be a bit "bulgy" (more conducive to lifting bodies or wing bodies) whereas with hydrocarbon-fueled vehicles, the concern is planform loading because of the high density fuel; thus, they may tend more towards waveriders which are not usually as volumetrically efficient. On the other hand, hydrocarbon fuels (endothermic) are limited in engine cooling capacity to below about Mach 8, depending on contraction ratio and dynamic pressure (ref. 1 ).

The airbreathing hypersonic horizontal-takeoff, horizontal-landing (HTHL) vehicles matrix being explored in Langley"s Hypersonic Airbreathing Systems Group/Vehicle Analy sis Branch/Aerospace Systems, Concepts and Analysis Competency (HASC/VAB/
ASCA) is presented in figure 1 along with the airbreathing corridor in which these vehicles operate. It includes endothermically-fueled theater defense and transport aircraft below Mach 8; above Mach 8, the focus is on dual-fuel and/or hydrogen-fueled airplanes for long range cruise, first or second stage launch platforms and/or single-stage-to-orbit (SSTO) vehicles.

The space-access portion of the matrix has been expanded and now includes pop-up and launch from hypersonic cruise platforms as well as vertical-takeoff. horizontal-landing (VTHL) launch vehicles. Also. activities at the NASA centers are becoming integrated; I ARC, GRC and MSFC are now participating in an advanced launch vehicle study of airbreathing systems for single-stage-to-orbit.

The cruise aircraft portion of the matrix has been focused on Mach 10 global reach designs for the past several years; this design activity led to the scramjet/ airframe integrated Hyper-X configuration (ref. 2) of which a 12 foot research vehicle is scheduled for flight tests at Mach 7 in 2000 and Mach 10 in 2001. The emphasis now is on resolving Mach 5 to 7 operational vision airplane designs and a requirements/technology flowdown to a Hypersonic Systems Integration Demonstrator (HySID), ref. 3).

The purpose of this paper is to present the status of the airbreathing hypersonic airplane and space-access vehicle design matrix, reflect on the synergies, convergencies and issues. and indicate the thrust of the effort to continue to resolve the design matrix with the goal of focusing advance systems technology maturation.

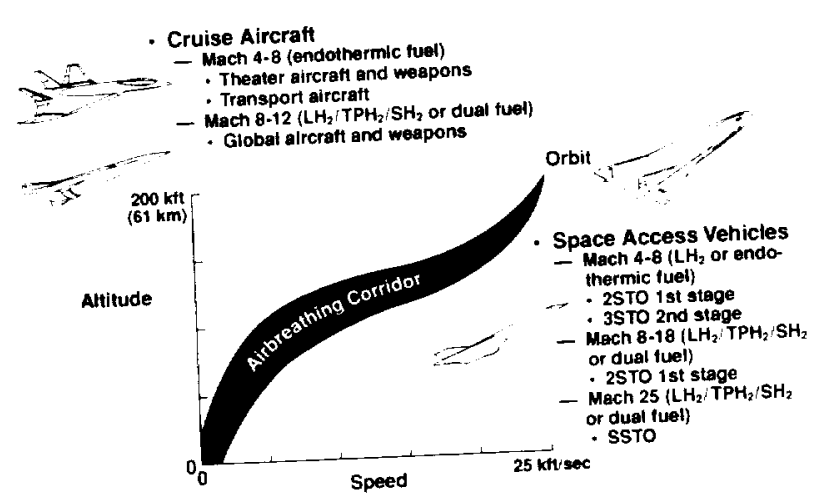

Figure 1. Potential airbreathing hypersonic vehicle applications. 


\section{AIRPLANES}

For hypersonic airplanes, range for a given payload at a given cruise Mach number is a good figure of merit (ref. 1). This figure of merit is impacted by the fuel selection. Calculations indicate that Mach 8 is approximately the cruise speed limit to which a dual-mode ramjet/scramjet can be cooled with state-of-the-art endothermic fuels/cooling-techniques (depending on flight dy namic pressure and inlet contraction ratio, ref. 1). On the other hand, liquid hydrogen has much more colling capacity and provides considerably more range than hydrocarbons for the same Mach number as indicated in figure 3 . The range of hydrogen-fueled vehicles maximizes at about Mach 10 (fig. 3), considerably beyond the cooling limits of the endothermic hydrocarbons. The takeoff gross weight (TOGW) of the hydrocarbon-fueled airplane is much greater for the same cruise Mach number than that for hydrogen-fueled airplane; the dry weight (DW) is slightly higher (ref. I).

The shape of the vehicle and the corresponding subsystems will be different for hydrocarbon-fueled airplanes than for the hydrogen fueled ones because of the fuel density and resultant planform to accommodate loading. Therefore, the discussion will be broken along these lines with the assumption that the speed breakpoint is Mach 8 even though hydrogen-fuel systems could be designed for lower cruise Mach number. The hybrid approach. dual-fuel, will be considered as a subset of hydrogen-fueled systems.

All hypersonic airplanes considered are underslungnacelle/engine-airframe integrated configurations in which the forebody serves as an external precompression surface for the engine inlet and the aftbody as a high expansion ratio nozzle. The differences are in whether the engine integration embodies a single duct or two-duct approach, or something in between.

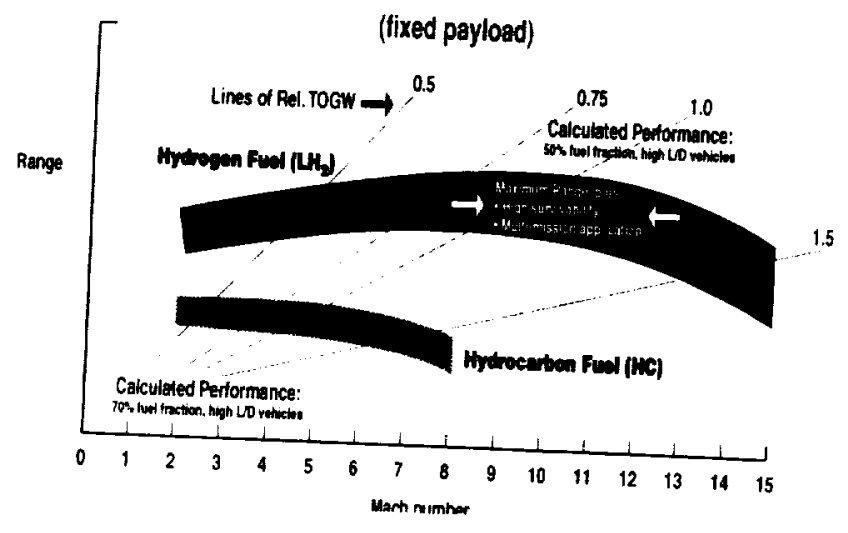

Figure 2. Range potential for hypersonic airplanes.

\section{DESIGN ARCHITECTURES}

The status matrix for hypersonic airplane designs is presented in references 4,5 and 6. It consists of a Mach 5. endothermically fueled, waverider configuration design (fïg. 3, ref. 4 ) and a Mach 10, dual and/or hydrogen fueled, lifting body configuration design (fig. 4 . refs. 5, 6). Both were designed for Recce/Strike/Suppression of Enemy Air Defenses (SEAD) missions and included $10 \mathrm{klb}$. payloads in $2,000 \mathrm{ft}^{3}$ payload bays.

Performance estimates for the Mach 5 waverider design indicate a $6,000 \mathrm{~nm}$ tanker-to-tanker range with a refueled gross weight of $550 \mathrm{klbs}$.; TOGW was $400 \mathrm{klbs}$. with a DW of 141 klbs., and a vehicle length of $113 \mathrm{ft}$. No dry weight growth margin was provided for this design.

The mission (fig. 6) radius of the Mach 10 dual fuel design would be about $8.500 \mathrm{~nm}$ in a $200 \mathrm{ft}$. long vehicle with a TOGW of $500 \mathrm{klbs}$. The mission would consist of take-off in a balanced field length of under $15,000 \mathrm{ft}$., acceleration and climb to hypersonic cruis-

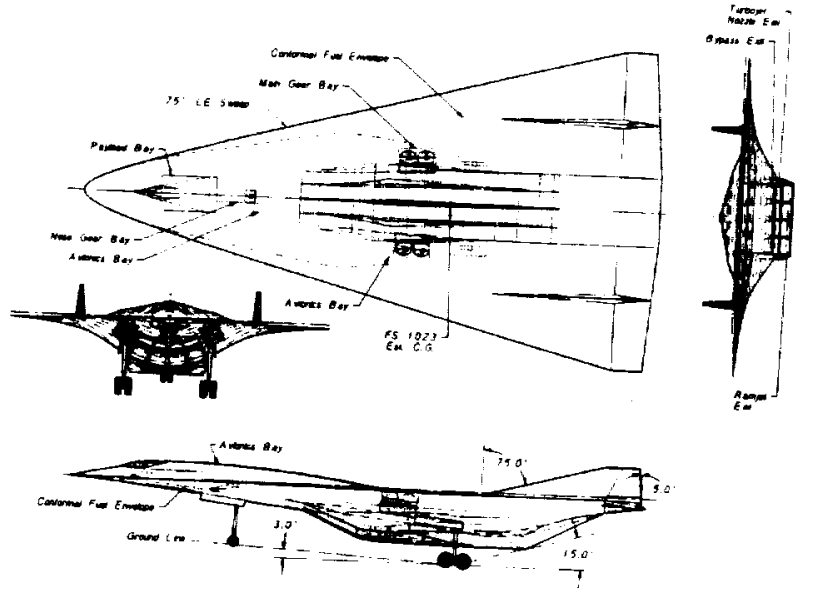

Figure 3. Waverider aircraft three-view.

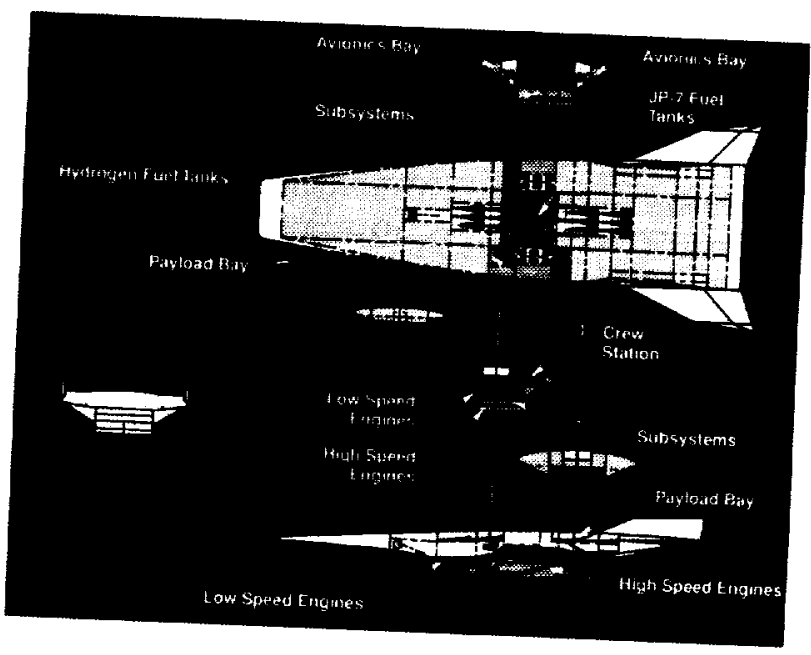

Figure 4. Dual-fuel lifting-body cruiser design. 
ing altitude and Mach number, Mach 10 cruise, completion of a $2.5 \mathrm{~g}$ turn at the target, and an unpowered. maximum $L / D$ descent to a subsonic rendezwous with tankers for a multiple endothermically refueled subsonic cruise return to base (fig. 5). The airplane would accelerate to Mach 4.0 on endothermically-fueled air core enhanced turboramjets (AceTRs) and transition to the hydrogen-fueled. dual-mode scramjet for continuation of the mission; the subsonic return segment is on the endothermically fueled AceTRs. A 10 percent dry weight growth margin was included in this design.

The Mach 5 waverider has a single inlet with a variable geometry, internal flow diverter for the over/under ducting downstream of the throat; whereas, the Mach 10 over/under engine integration has separate split inlets (ref. 3); the two-inlet approach provides the shortest inlet/diffuser system. The Mach 5 vehicle has a single thermal management system employing endothermic fuel for active cooling of the critical systems and engine. The Mach 10 vehicle has two active cooling systems although integrated: the endothermic system is similar to that for the Mach 5 vehicle. but at Mach 4 to 4.5 the cooling load is switched to a separate but interwoven hydrogen circuit (ref. 3 ).

The structural architecture is totally different for the two airplane designs. The Mach 5 design would consist of a hot structure with integral tanks lined with insulation and containing flexible fuel cells (ref. 4) for endothermic/noncryogenic fuel. Honeycomb sandwich panels of a monolithic titanium alloy were selected for airframe skins. Wing and tail leading edges were designed with a titanium matrix composite (TMC).

The airframe for the Mach 10 cruise airplane was a cold structure with integral slush-hydrogen ( $\mathrm{SH} 2$ ) tanks (fig. 5, ref. 7). Triple-point hydrogen fuel (TPH) is now being emphasized since it has the same vapor pressure as $\mathrm{SH}_{2}$ and thus can use the same tank design but without stirrers and mixers; there is a 5 percent density penalty.

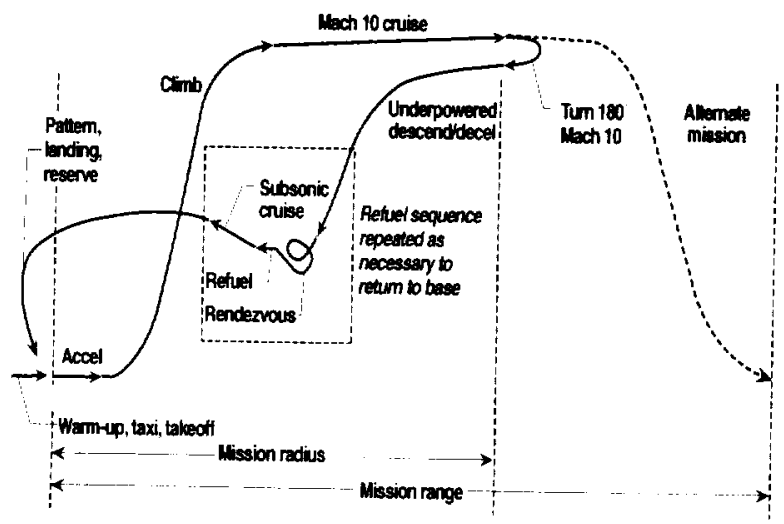

Figure 5. Candidate hypersonic cruise mission scenarios.
A conformal graphite-epoxy ( $\mathrm{Gr} / \mathrm{Ep})$ tank design would be used since the maximum pressure differential for the slush hydrogen tank is only 5 psi. Graphite composite would constitute the remainder of the fuselage structure. The all-moveable wings would be hot structure (TMC). The thermal protection system would consist of Internal Multiscreen Insulation (IMI) covered with a heat shield of carbon/silicon-carbon $(\mathrm{C} / \mathrm{SiC})$ panels on the windward surface and a Tailorable Advanced Blanket Insulation (TABI) on the lee surface.

\section{EMPHASIS FOR FUTURE AIRPLANE, DESIGN ACTIVITIES}

In the Mach 10, Dual-Fuel airplane design study, osculating-cone waverider (ref. 9) and lifting-body configurations were examined. The aerodynamic efficiency (L/D) build up for these configuration classes is given in figure 6, ref. 10. The inviscid $L / D$ favors the waverider, but the trimmed $\mathrm{L} / \mathrm{D}$ at Mach 10 was the same. The lifting-body configuration was selected in the Mach 10 Dual-Fuel study because it is closer to a Sears-Haack area distribution, had higher fineness ratios and thus lower drag in general and lower transonic drag in particular. The latter is very important since it sizes the low speed engines (in the over position) which are coupled in mechanical integration to the sizing of the high-speed engines (in the under positions). The high speed engines were sized for acceleration from Mach 4.5 to 10 and to accommodate an appropriate lower throttle position at Mach 10 cruise to maximize the product of $\mathrm{L} / \mathrm{D}$ and specific impulse (Isp).

The above perspective suggests that perhaps the use of the classic waverider configuration below Mach 8 (fig. 3) as an optimum approach should be reexamined. This may be correct, but it should be kept in mind that at Mach 10 and above. the lifting-body is a quasi-waverider itself. Below Mach 8 with the exclusive use of hydrocarbon/ endothermic fuels, the higher density of the fuel would place more emphasis on loading and lifting capability. which is an attribute of the waverider. Also, subsequent

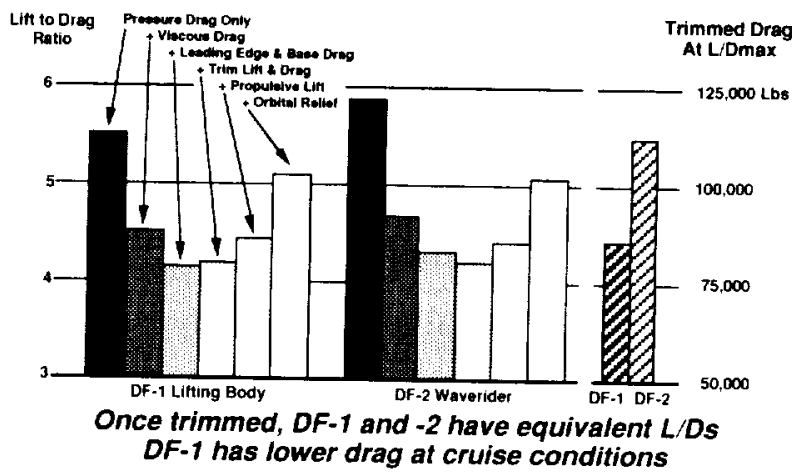

Figure 6. Aerodynamic results for configurations $D F-I$ and 2. 
analysis has shown that a relaxation in the planar shock width constraint of the osculating-cone waverider can reduce the width and associated trim drag of the configuration (ref. 9). Nevertheless, the results of the Hypersonic Systems Integration Demonstrator (HySID) study (ref. 10) suggest that a lifting-body-derivative configuration should bx given consideration in an endothermically-fueled operational, vision vehicle design study for airplanes with cruise speeds below Mach 8, but as scale/loading increases. the favorable lift of the waverider configuration may become the desirable selection characteristic.

\section{MACH 7, OPERATIONAL VISION-VEHICLE STUDY}

LaRC and AFRL (Air Vehicles Dir. and the HyTech Program Office) are jointly sponsoring an operational Mach 7 Vision Vehicle Design Study constrained to hydrocarbon/endothermic fuels. Designs for Uninhabited Combat Air Vehicles (UAV's), Reconnaissance (Recce) and Global Reach scenarios are being examined.

The engine integration architecture is an underslung nacelle, with forebody precompression and aftbody nozzle expansion, containing an over/under engine arrangement; turboramjets are in the over position with dual mode ramjets in the under positions. Within this engine integration constraint, the aircraft configuration is still an issue in the same manner alluded to in the previous section.

For smaller aircraft such as the UAV's and some Recce vehicles, the lifting body with its lower transonic drag is more suitable, but unlike the (horizontal controls) rotating wing Mach 10 Global Reach, dual fuel and/or all hydrogen designs, it must have fixed wings to provide the lift needed for the high density hydrocarbon fuel load: the fixed-wings necessitate a canard for rotation on takeoff. Such a configuration is shown in figure 7.

This fixed-wing lifting-body approach has scale limitation in that load is increasing as length cube and lift as length squared; thus, designs to accommodate Global

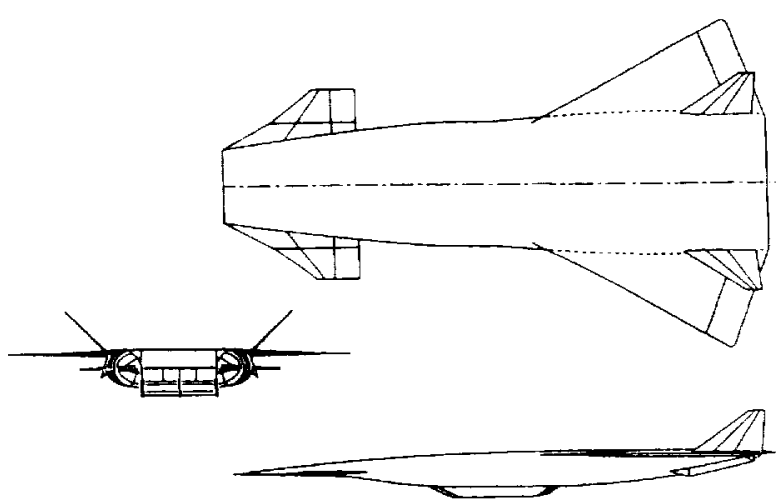

Figure 7. HySID Canard-Wing Configuration concept.
Reach scenarios (7000 nmi plus from tanker to tanker) may revert back to a more classic waverider because of the emphasis on lift to carry the fuel load. The study is in the midst of understanding the issues as well as expanding the scope to include Mach 5 to 7 aircraft in which the Mach 5 vehicle may not require underslung dual mode ramjets.

\section{SPACE-ACCESS VEHICLES}

Airbreathing space-access vehicles potentially have takeoff gross weight and mission flexibility (launch window, orbital offset, rapid rendezvous, etc.) advantages (fig. 8) over their rocket powered counterparts. The relative disadvantages of present airbreathing designs lie in technology readiness and dry weight (ref. 7), both of which impact initial cost. The goal here is not only to reflect the status of the airbreathing spaceaccess design matrix, but indicate the potential to advance the design matrix toward eliminating the aforementioned relative disadvantages. Of course. operations is a major cost of any reusable launch system; this is yet to be resolved in favor of either the airbreather or rocket propelled systems and will require a more extensive prediction capability/database than presently exists.

\section{SINGLE-STAGE-TO-ORBIT VEHICLES}

A design study was performed using an HTHL SSTO airbreathing-propelled orbital vehicle with rocket propulsion augmentation in NASA's Access-to-Space study (ref. 11 and 12; Option III Team). This design (fig. 9) provided a reference architecture. It was designed to carry 25 klbs. of payload in a $15 \mathrm{ft}$. $x 15 \mathrm{ft}$. x $30 \mathrm{ft}$. rectangular payload bay with shuttle-like doors to an orbit of $220 \mathrm{~nm}, 51.6^{\circ}$ inclination (reference mission), then dock with a hypothetical space station for delivery of the payload. It had a $15 \%$ weight growth margin, a 5-minute launch window. and an ascent delta

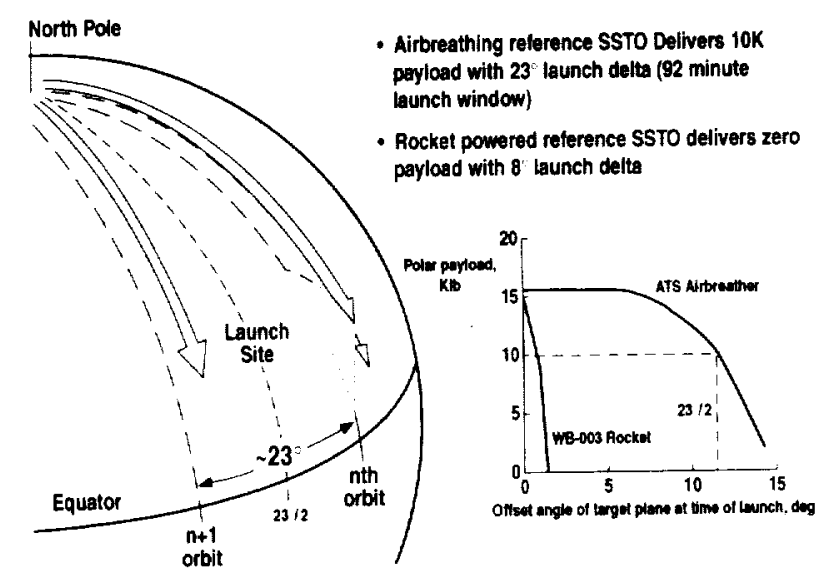

Figure 8. Rapid rescue/rende-vous. 
velocity margin of $1 \%$. The TOGW (sized for the closed mission) was $917,000 \mathrm{lbs}$., the DW was 239,000 lbs., and the length was $200 \mathrm{ft}$.

\section{SSTO Vision Architecture}

The reference design (fig. 9, ref. 13) consisted of:

- A spatula-shaped forebody planform, lifting-body configuration with all-moving horizontal tails, twin vertical tails, and trailing edge body flaps.

- Underslung. 2-D airbreathing engine nacelle; two engine systems with $1.30 \mathrm{klbs}$, of thrust each at takeoff.

- A linear, modular, aerospike rocket engine at the trailing edge; two engine systems with $117 \mathrm{klbs}$. $(520 \mathrm{kN})$ of thrust each at takeoff.

- SH2 and LOX propellant (about a 50/50 split by weight).

- Actively-cooled leading edges (fuselage spatulashaped region and engine cowl); actively cooled. non-integral panels in engine.

- Two 6-wheel main landing gears; one nose gear (two wheels).

- A Gr/Ep integral, I-stiffened, conformal SH2 tank; Aluminum/lithium non-integral, multilobe LOX tanks.

- Gr/Ep shell structure fore and aft of integral tank: TMC horizontal and twin vertical controls with C/SiC TPS and carbon-carbon (C/C) leading edges.

- Fibrous Refractory Composite Insulation (FRCI-12) TPS windward surface and Tailorable Advanced Blanket (TABI) over Rohacell insulation on leeward surface.

\section{Trajectory/Engine Modes}

The airbreathing corridor to Mach 25 and the engine mode changes experienced in this acceleration process also characterize this aerospace plane. A representative ascent trajectory (ref. 10) for the SSTO vehicle is presented in figure 10 including indicators for propulsion mode events. Most of the airbreathing propelled ascent is along a high dynamic pressure isobar (21.50 psf).

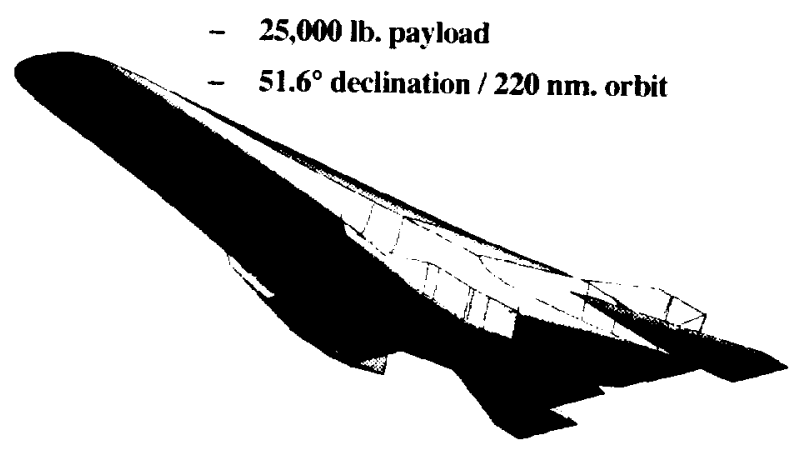

Figure 9. Reference airbreathing SSTO vehicle.

\section{Emphasis For Future SSTO Design Activities}

The reference lifting-body SSTO design was reexamined in the two past years. The original TPS of FRCI$12 / \mathrm{TABI}$ was replaced with purged $\mathrm{IMI} / \mathrm{TABI}$, and a parametric study was performed by Dennis Petley. This study was performed to determine the impact on TPS weight of new TPS dynamic pressure in the airbreathing segment of the trajectory and pull-up Mach number in transitioning to rocket propulsion. The results are given in figure 11. For the baseline trajectory (fig. 10 , $q=2150 \mathrm{psf}$, pull-up Mach $=16.5$ ), the IMI/TABI retrofitted TPS saved $4593 \mathrm{lbs}$. (16\%) and included a purge system which, with an umbilical. would allow an indefinite hold time at takeoff assuming that the $\mathrm{SH} 2$ tank is topped-off. The impact of airbreathing trajectory segments at lower dynamic pressure and earlier pull-up Mach number on reducing TPS weight was essentially insignificant. Lower dynamic pressure results in slower acceleration and longer ascent times so that there is very little change in total heat load. For the earlier pullup Mach number, the heat load was somewhat balanced by the required higher angle-of-attack.

The design was also modified for Mach 12 shockon-lip instead of the original Mach 1.5 by Zane Pinckney and Lawrence Taylor; substantial performance and trim benefits were realized. However, an omission was found in the original drag accounting that resulted in a higher closure weight (TOGW $-1.000 \mathrm{klbs}$., DW $250 \mathrm{klbs}$.). The Vehicle Analysis Branch at LaRC projects that for the same technology levels (SH2, etc.), vertical takeoff, horizontal landing rocket propelled SSTO designs would have a dry weight near $190 \mathrm{klbs}$. Thus, in order to drive the dry weight of the airbreathing SSTO below the reference lifting-body design (fig. 13) and toward that projected for SSTO vertical takeoff rocket vehicles, different configurations and subsystems need to be explored.

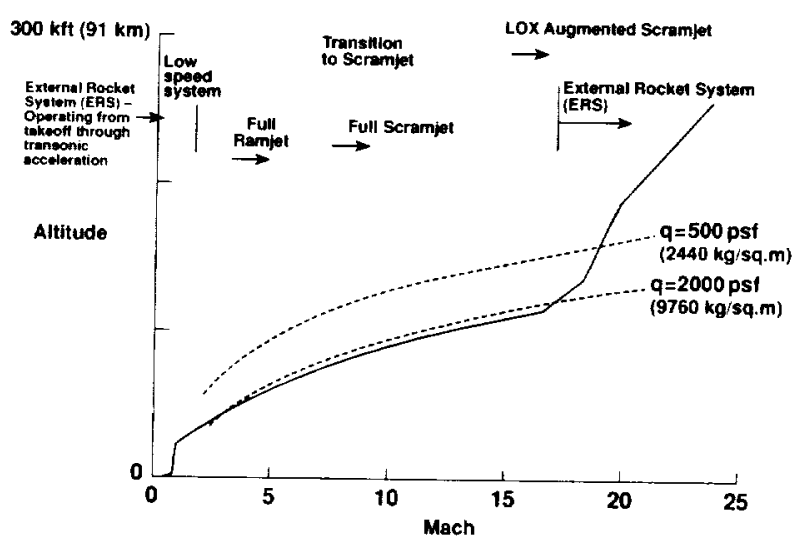

Figure 10. Representative ascent trajectorv: 


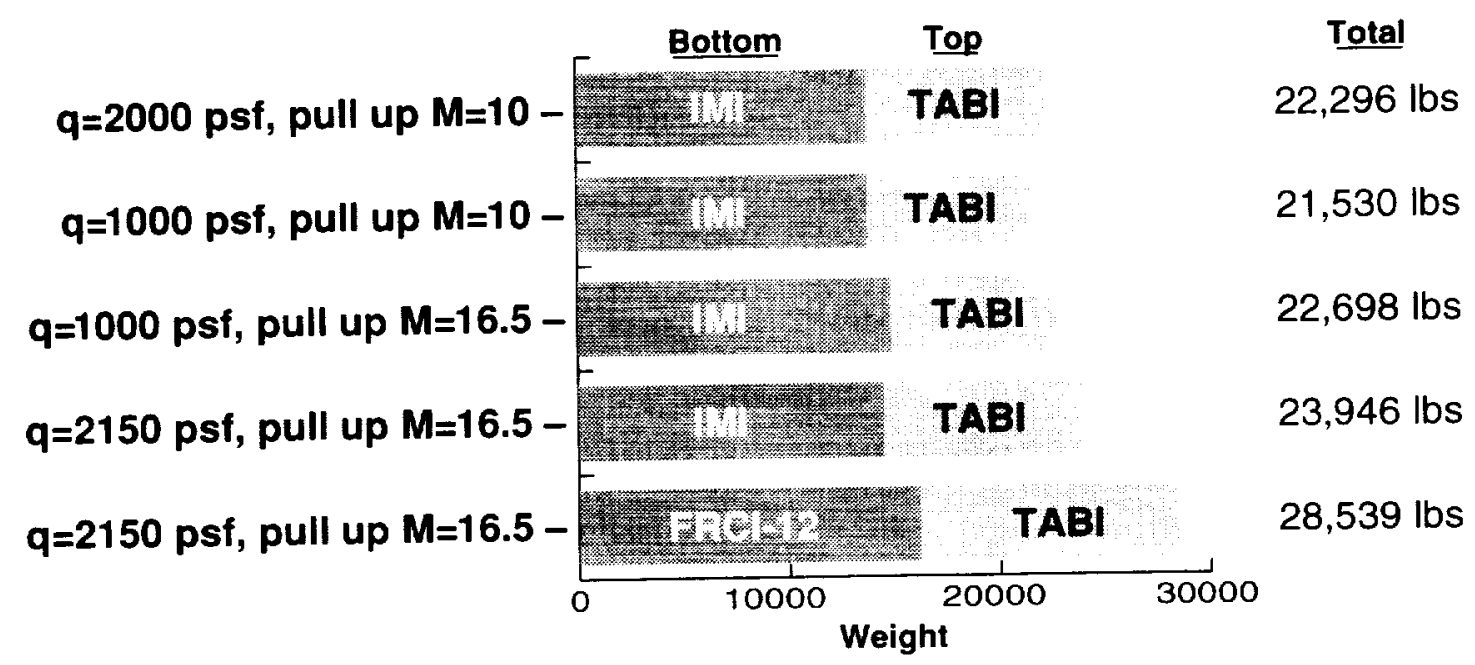

Figure 11. TPS weight for airbreathing Access-to-Space vehicle.

Configurations

Other HTHL SSTO configurations of interest in VAB are shown in figure 12 . Recent examination of an inverted lifting body was disappointing: it performed well subsonically, but lacked sufficient lift at the required low angles-of-attack during supersonic/hypersonic acceleration, except near shock-on-lip conditions.

The problem with the underslung engine, liftingbody configuration with rotating horizontal controls (reference vehicle) is that in order to keep the takeoff speeds below 300 knots, the fineness ratio was forced below 6 whereas a fineness ratio near 7 would be more optimum for this configuration engines at hy personic speeds. Therefore. larger drag losses accrued across the Mach range because of takeoff constraints. In order to reduce drag losses during ascent, a high fineness ratio (-9) wing body was examined. These higher fineness ratio, fixed-wing configurations have lower drag per unit volume relative to the lifting body and thus require less engine size but more wing. Also, the fixed wing approach may allow the use of a localized hydraulic system rather than the centralized approach of the reference SSTO (fig. 9).

The high fineness ratio vehicle designs can only approach the levels of effective specific impulse of the lifting body (the propellant fraction required); it is on the propellant fraction achievable (design/packaging) that it must considerably exceed the capability of the lifting body to provide a more viable approach. In the present study it was not able to do this, and thus lost out to the lifting body.

A very promising hypersonic air-breathing configuration in terms of propulsion flow path is the inward turning configuration (ref. 14). Ideally, the funnel-like inlet configuration offers more air capture and more efficient compression to the inlet throat for less wetted area than does its two-dimensional or conical counterparts. This characteristic could result in potentially higher net thrust and specific impulse.

An inward-turning inlet concept was suggested for use with missile designs by Jim Keirsey of APL/JHU in the 1960s (ref. 15). During the NASP years, an inward-turning propulsion flow path approach was suggested for use with SSTO systems by Bob Jackson of LaRC (ref. 16); packaging and off-design performance were concerns (ref. 17). LaRC and MSFC have recently been pursuing the inward-turning concept for SSTO vehicle designs with Astrox Corporation; an innovation suggested by Astrox/Pyrodyne to hopefully remedy earlier concerns is now being examined.

LaRC, GRC and MSFC are now participating in an Airbreathing Launch Vehicle (ABLV) systems study as a part of the Advanced Reusable Technologies (ART) Project/Advanced Space Transportation program (ASTP). The SSTO configuration matrix being explored encompasses horizontal and vertical takeoff/horizontal

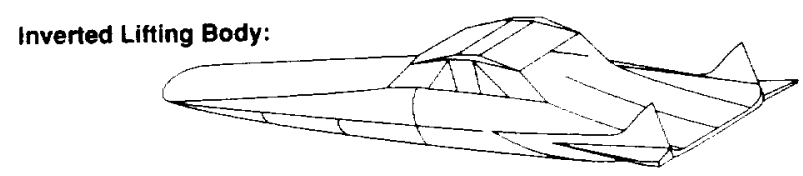

High Fineness Ratio Wing Body:

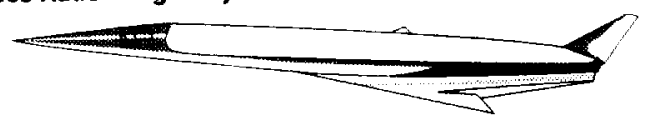

Inward Turning Flowpath (Funnel) Configuration:

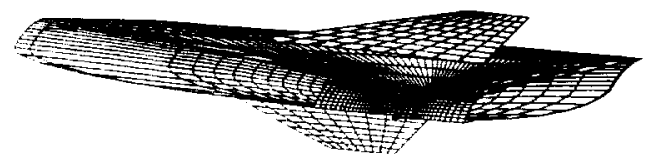

Figure 12. Extended/advanced configuration matrix. 
landing vehicles using ejector-ramjet/dual-mode scramjet/ejector scramjet/ejector rocket (rocket-based combined cycle, RBCC) propulsion systems: the design matrix for the study is given in figure 13.

Propulsion Systems

In the initial exploration of the aforementioned configuration matrix, a standard set of subsystems is being used with emphasis on RBCC engines. The ejector ramjet operates from takeoff to ramjet take over speed (M-3); the dual-mode ramjet/scramjet operates to Mach 10 or 15 , depending on the pull-up Mach number which in turn depends on the installed thrust-to-weight of the engines and the takeoff mode (horizontal or vertical), where the ejector rocket is again ignited to operate simultaneously with the scramjet (ejector scramjet or LOX augmented scramjet) and/or eventually alone as a rocket in a duct (inlet closed off). Thus, a single duct engine that operates over a broad Mach range is possible (ref. 7 ).

The RBCC (high density LOX that provides potential planform loading problems for unassisted horizontal takeoff SSTOs) requires a considerable amount of oxidizer and thus a system that extracts oxygen from the atmosphere would be more optimum. This system which extracts air. condenses it, and uses it in the ejector ramjet is a liquid air cycle engine (LACE, ref. 18). It is being examined as a reference in the design study in conjunction with $\mathrm{SH} 2$ fuel. Air collection and enrichment systems (ACES) where liquid oxygen is subsequently separated out and stored is also of interest for SSTO's. MSE Inc. is testing vortex tubes for this separation task including examining their integration with LACE under a contract with NASA.

Turboramjets are being examined as low-speed

\begin{tabular}{|c|c|c|}
\hline \multicolumn{3}{|c|}{ (Access-to-Space Mission, SSTO Architectures) } \\
\hline HTHL & $\begin{array}{l}\text { - Lifting Body } \\
\text { - Ref./ATSD } \\
\text { - RBCC/PW } \\
\text { - RBCC/RD } \\
\text { - RBCC/AJ } \\
\text { - PDE/ATS (LM) } \\
\text { - AceTR/ATSD } \\
\text { - PDE/ATS (Boeing) } \\
\text { - High Fineness Ratio } \\
\text { - Ref./ATSD } \\
\text { - Inward Turning } \\
\text { - RBCC/Astrox }\end{array}$ & $\begin{array}{r}\text { Designation } \\
\text { ablv-4 and } 4 a \\
\text { ablv-5 } \\
\text { ablv-6 } \\
\text { ablv-7 } \\
\text { ablv-8 } \\
\text { ablv-4b and } 9 \\
\text { ablv-4c and } 10 \\
\text { ablv-1 } \\
\text { ablv-2 and } 2 a\end{array}$ \\
\hline$V T H L$ & $\begin{array}{l}\text { - Axisymmetric/Conical } \\
\text { - RBCC/PW } \\
\text { - RBCC/RD } \\
\text { - RBCC/AJ } \\
\text { - Cone Cylinder } \\
\text { - Hali-spike/GRC }\end{array}$ & $\begin{array}{r}\text { spike-pw } \\
\text { spike-rd } \\
\text { spike-aj } \\
\\
\text { trail-1 }\end{array}$ \\
\hline
\end{tabular}

Figure 13. ABLV vision vehicle design matrix. propulsion systems for unassisted horizontal takeoff SSTO vehicles. They would integrate in an underslung, over/under two duct system with the turboramjet in the over position and the dual mode ramjet in the under position much like the Mach 10 Dual Fuel Airplane discussed previously. The transition from the turbine to the dualmode ramjet would occur in the Mach 4 to 4.5 range. The advantage of the turbine is that it would require no LOX during its operation and thus reduce the LOX fraction required for closure and thus reduce planform loading and takeoff speed concerns. High thrust per unit cross-section and high thrust to weight would be some of the characteristics sought for these turbine engines.

Pulse detonation engines (PDE), in which detonation waves propagate through a premixed fuel-air mixture to produce large chamber pressures and thereby thrust, are potentially promising for low speed ( $M=0$ to 5) propulsion (ref. 19). Pulse detonation rockets (PDRE) could be used for pull-up and exoatmospheric operations. They would integrate in two-duct, over/under architectures much like the turbines. These systems are also being examined in the LaRC, GRC and MSFC Airbreathing Launch Vehicle (ABLV) systems study (fig. 13).

\section{TWO-STAGE-TO-ORBIT (TSTO) VEHICLES}

The attractiveness of TSTO systems is versatile basing with airplane-like operations. launch offset capability and nearerterm technology (ref. 7) than SSTO vehicles. For launch systems that stage at Mach 6 or below, the booster could be designed with near-term technology. Boosters that stage above Mach 6 are grealer design challenges and would require more advanced technology because of the need for a dual-mode scramjet and more sophisticated/thicker TPS. With their ability to cruise, airbreathing boosters have the potential to return to multiple landing sites. including the launch site, even at the higher staging Mach numbers.

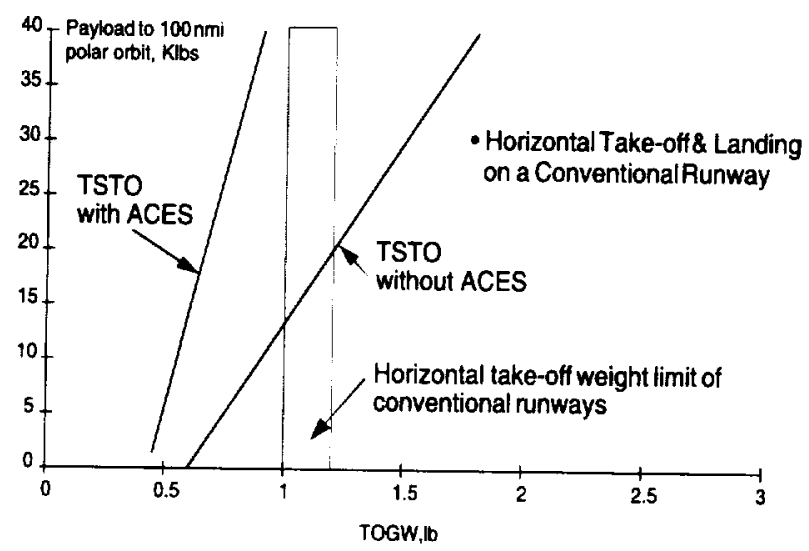

Figure 14. Impact of ACES on payload delivery of TSTO system (piggy-back...stage at $M=5$ ). 
Staging at Mach 5

(Piggy-Back)

HTHL airbreathing launch configurations with piggy-back, rocket-powered orbiters nested on top have been examined rather extensively in the literature. A reference vehicle of this type (ref. 20) that is similar to the lifting-body of figure 9 and is from NASA's Access-to-Space study (ref. 10). It would stage at Mach 5 and perform the Access-to Space mission with a combined TOGW of $800 \mathrm{klbs}$. and DW of $300 \mathrm{klbs}$. The combined weights continue to slightly decrease with increasing staging Mach number, at least to Mach 12 (ref. 20), but the design/technology challenges increase.

One of the more interesting designs of the piggyback approach is reported in reference 21 in which an air liquefaction system with a mechanical oxygen/nitrogen separator (Air Collection and Enrichment System, ACES) was integrated into the first stage. Liquid air was collected from Mach 2.5 to 5 with the separated oxygen pumped to the rocket-propelled upper stage which deployed at Mach 5. The advantage over systems without ACES was almost a factor of two less in TOGW for payloads on the order of $30 \mathrm{klbs}$. (fig. 14).

The focus of the discussion herein (studies conducted or sponsored by LaRC) will be on two stage horizontal take-off and landing systems in which the payload (upper stage) is enclosed within the first stage (launch vehicle)

\section{Staging Al Mach 8} (2nd Stage Enclosed Within Ist)

An initial design of a second generation TSTO vehicle (ref. 22), with an airbreathing $\mathrm{LH} 2$ fueled first stage,
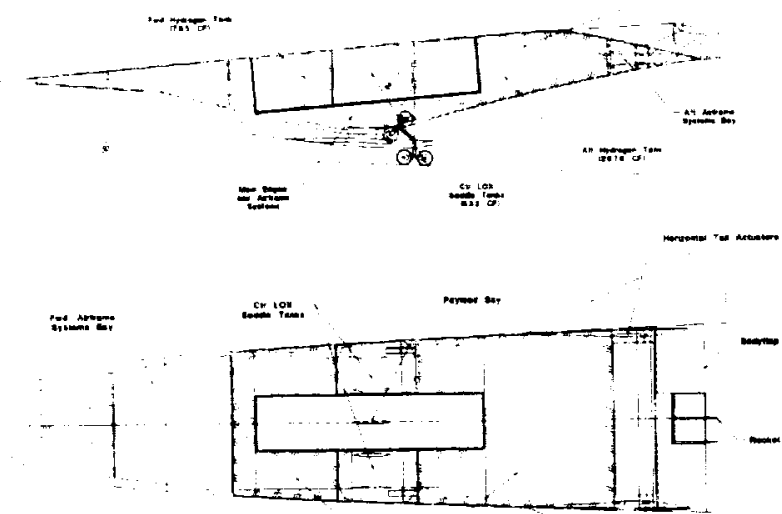

mand

Figure 15. Advanced Reusable Small Lannch Sistem (ARSLS) airbreathing booster vehicle. capable of delivering 2,000 Ibs. payload to orbit is presented in figure 15. Two low-speed propulsion systems were considered for the first stage vehicle for Mach 0 to 3 operation, a LOX ejector ramjet (RBC C) and an air-core enhanced turboramjet engine (AceTR). A dual-mode ramjet was used above Mach 3 for both low-speed systems, but the RBCC allowed the use of a single-duct while the AceTR integration required the use of two ducts (over/under). The airframe structure/ TPS design was the same as that for the reference SSTO (fig. 9).

The second stage was a Centaur-based concept with a LOX/hydrogen powered $\mathrm{RI}$ - 10 rocket engine. It was sized to deliver a $2 \mathrm{klb}$. payload out of a $7 \mathrm{ft}$. diameter. $10 \mathrm{ft}$. long bay from a staging Mach number of 8 (near optimal for design/mission) to a $100 \mathrm{~nm}$ easterly orbit. Staging dynamic pressure was below 1 psf to accommodate separation and eliminate aerodynamic drag on the second stage. Dry weights ranged from $67 \mathrm{klbs}$ to 69 klbs. and take-off gross weights ranged from $119 \mathrm{klbs}$ to $131 \mathrm{klbs}$., depending on the low-speed propulsion system (Ace'TR system was lightest, fig. 16). A three-stageto-orbit system was also considered with this configuration/ architecture ( 2 nd and 3 rd stages) with the first stage being a platform for a Mach 0.8 launch (fig. 16); only a $10 \mathrm{kJb}$. reduction was realized in the TOGW of the combined 2 nd and 3 rd stages.

\section{Staging at Mach 10 (2nd Stage Enclosed Within Ist: Dual Role for Mach 10 Dual Fuel)}

The study originally scheduled as Phase II of the DualFuel Airbreathing Hypersonic Vehicle Design Study (ref. 5) in which the possibility of using a derivative of the Mach 10 Global Reach vehicle as a launch platform for an enclosed upper stage was recently completed by Boeing (ref. 23). More range potential was obtained with a slightly higher fineness ratio, deeper body version of the baseline Mach 10 vehicle (fig. 5). This alter-

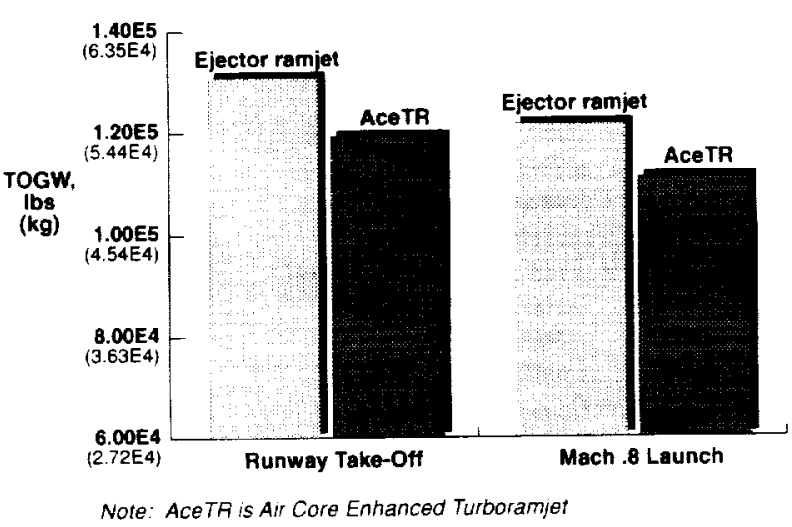

Figure 16. ARSLS design trades. 


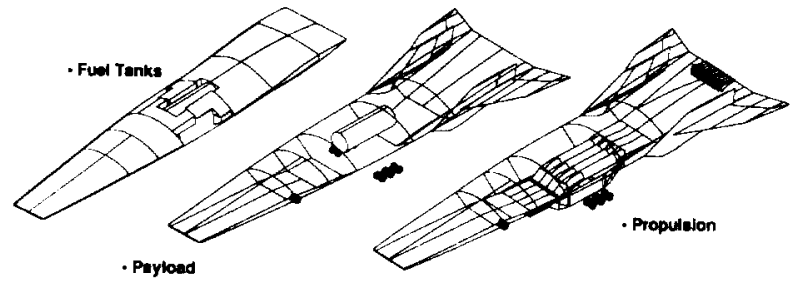

Figure 17. Cruiser/Space Launch Vehicle; DF-9 configuration.

nate vehicle was modified to include a cylindrical payload bay ( $10 \mathrm{ft}$. diameter, $30 \mathrm{ft}$. long) to contain an upper stage based on an ATLAS IIA design and a 150 $k \mathrm{lb}$. thrust linear aerospike rocket in the aft-end for pull-up assist (fig. 17).

The low speed propulsion system for the modified Cruiser/Space Launch Vehicle was sized in conjunction with the tail rocket to accelerate through the transonic speed regime and a reaction control system (RCS) was used to provide stability and control during the high altitude pop-up flight. As a launch system (fig. 18), the

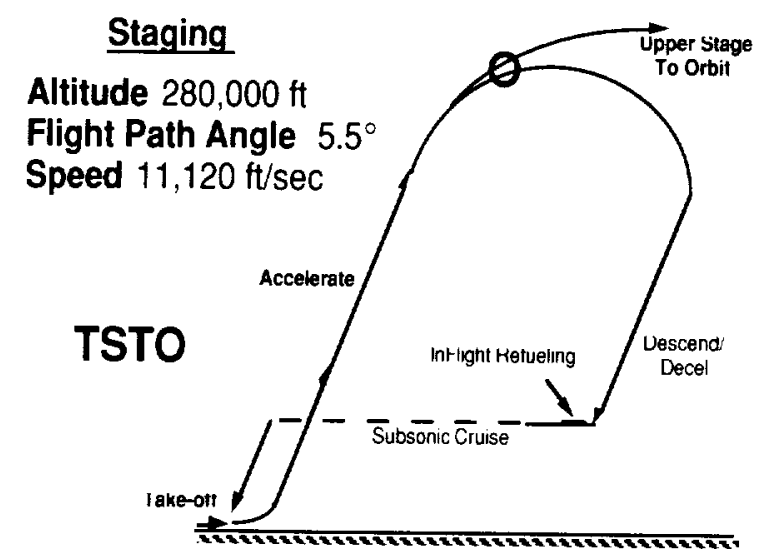

TOGW is $532 \mathrm{klbs}$. Staging occurs at an altitude of 280 $\mathrm{kft}$., a flight path angle of $5.5^{\circ}$ and a velocity of 11.120 $\mathrm{ft} / \mathrm{sec}$; a payload of $5 \mathrm{klbs}$. is delivered to a low-earth easterly orbit by a $30 \mathrm{klb}$. upper stage. As a cruise system (fig. 18) with a $10 \mathrm{klb}$. payload. TOGW is 521 klbs.; the mission radius is $7400 \mathrm{~nm}$ with refuelings required for the subsonic return. An all-slush hydrogen fuel version had a TOGW of $441 \mathrm{klbs}$. for the Space I aunch Mission and a TOGW of $370 \mathrm{klbs}$. for the Cruise Mission with a range of $7600 \mathrm{~nm}$ (fig. 19).

An RBCC variant was also examined. The two-duct over/under engine integration was replaced by a singleduct generic RBCC with an installed, take-off thrust-toweight of 27. the separate tail, linear rocket was removed and the JP-7 fuel tanks were replaced with LOX tanks. For the space launch mission. the RBCC vehicles TOGW was $589 \mathrm{klbs}$. including the $30 \mathrm{klbs}$. second stage enclosed payload. For cruise, the vehicle's TOGW was only $511 \mathrm{klbs}$. with a $10 \mathrm{klbs}$. cruise payload; the vehicle cruised to $9.36+\mathrm{nm}$, again on a direct route without a turn and including descent.

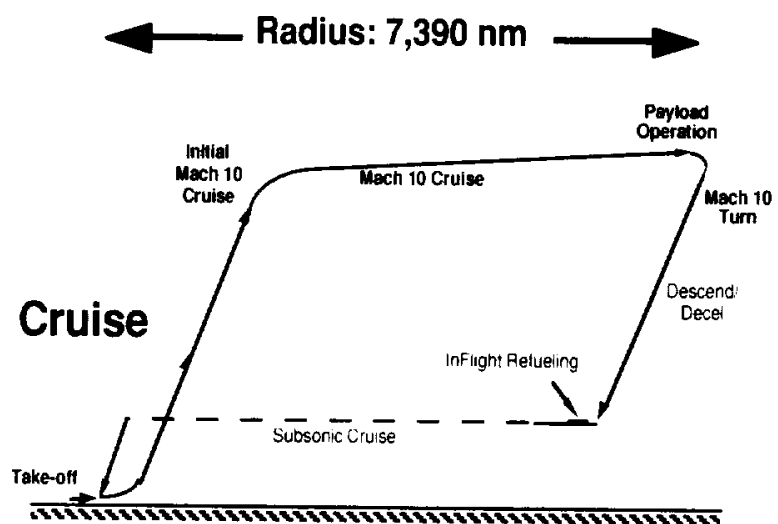

Cruise Mission TOGW: 520,762 lb

\section{Space Launch Mission TOGW: $531,987 \mathrm{lb}$}

Figure 18. Dual-fuel performance ( $D F-9$ configuration).

Staging

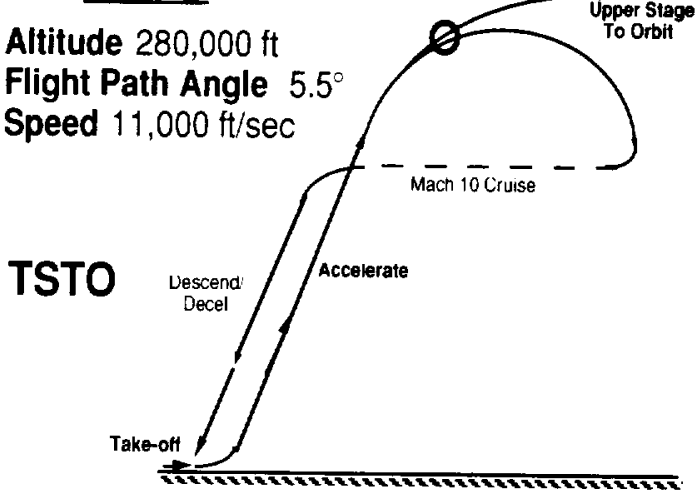

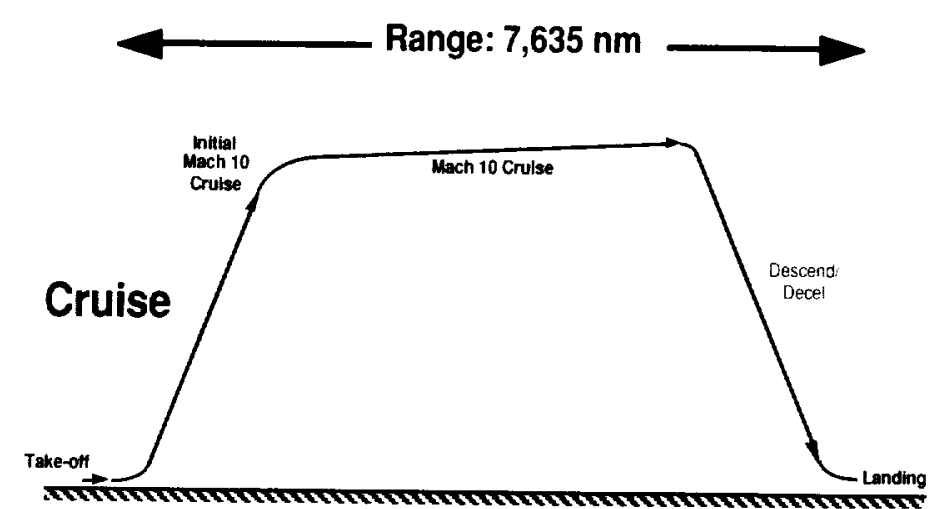

$\rightarrow$ Landing

\section{Space Launch Mission TOGW: 441,286 lb Cruise Mission TOGW: $370,139 \mathrm{lb}$}

Figure 19. All-hydrogen performance (DF-9 configuration). 
Boost glide capabilities with sinusoidal trajectories have been examined with this concept and are shown to be a detriment for this design versus cruise in terms of range.

\section{SUMMARY}

The thrust in airbreathing hypersonic system studies at LaRC is to advance the configuration design matrix for airplanes and space-access vehicles. This operationalvision-vehicle matrix includes flowdown requirements for flight research vehicles whose flight demonstrations will in turn provide the technology maturation/capabilities leverage that enhances the probability that these vision vehicles will reach fruition (fig. 20 ).

Concerning airplanes, the emphasis is on Mach 5 to 8 endothermically-fueled designs and Mach 8 to 10 hydrogen and/or dual-fuel designs. The issue at present is whether a derivative of the lifting body that was used in the Mach 10 dual-fuel and/or hydrogen-fueled designs will replace the classic waverider as a more optimum configuration for the endothermically fueled Mach 5 to 8 designs. This issue is focused around transonic drag which sizes the low-speed engines in over/under integration schemes and does not presently appear to favor the waverider. Of course, the level of trimmed, cruise aerodynamic efficiency is very important in this discrimination, but it was not a factor in the Mach 10 global reach, dual-fuel study (ref. 5, no difference in trimmed L/D). A Mach 7 vision-operationalvehicle (endothermic fuel) design study is in progress and should help resolve this issue. However, there is probably a mixed picture here, with the smaller vehicles (lower loaded) tending toward the lifting-bodies and the larger vehicles (higher loading) tending toward the waveriders.

For space-access vehicles, the focus is on SSTO and TSTO vehicle systems design. For unassisted, horizontal-takeoff SSTO vehicles, lifting bodies with underslung airbreathing engines are being examined for various fineness ratios. The higher degree of airbreathing (turbines, etc.) with the lower LOX fraction will probably optimize to the higher configuration fineness ratio-higher thrust-to-drag ratio; the higher degree of rocket mode ( $\mathrm{RBCC}$, etc.) will probably optimize to the lower fineness ratios - higher thrust to weight ratios. Inward-turning propulsion flow path configurations are also being examined. All of this work is being accomplished in the Airbreathing Launch Vehicle (ABLV) study, jointly supported by LaRC, GRC, and MSFC. This activity is being conducted under the Advanced Reusable Transportation (ART)/Advanced Space Transportation Program (ASTP).

As for TSTO systems, a study was just completed to modify the Mach 10, Global Reach, dual-fuel and/or hydrogen fueled airplane to include a pop-up/launch capability to deliver 5 to $8 \mathrm{klbs}$ to low earth orbit (LEO) through a rocket-powered upper stage. Not only did the payload delivery from a Mach 10 launch platform appear viable, but the linear aerospike rocket installation in the trailing edge of the airplane to allow staging at low dynamic pressures did not appreciably deter its cruise capability.

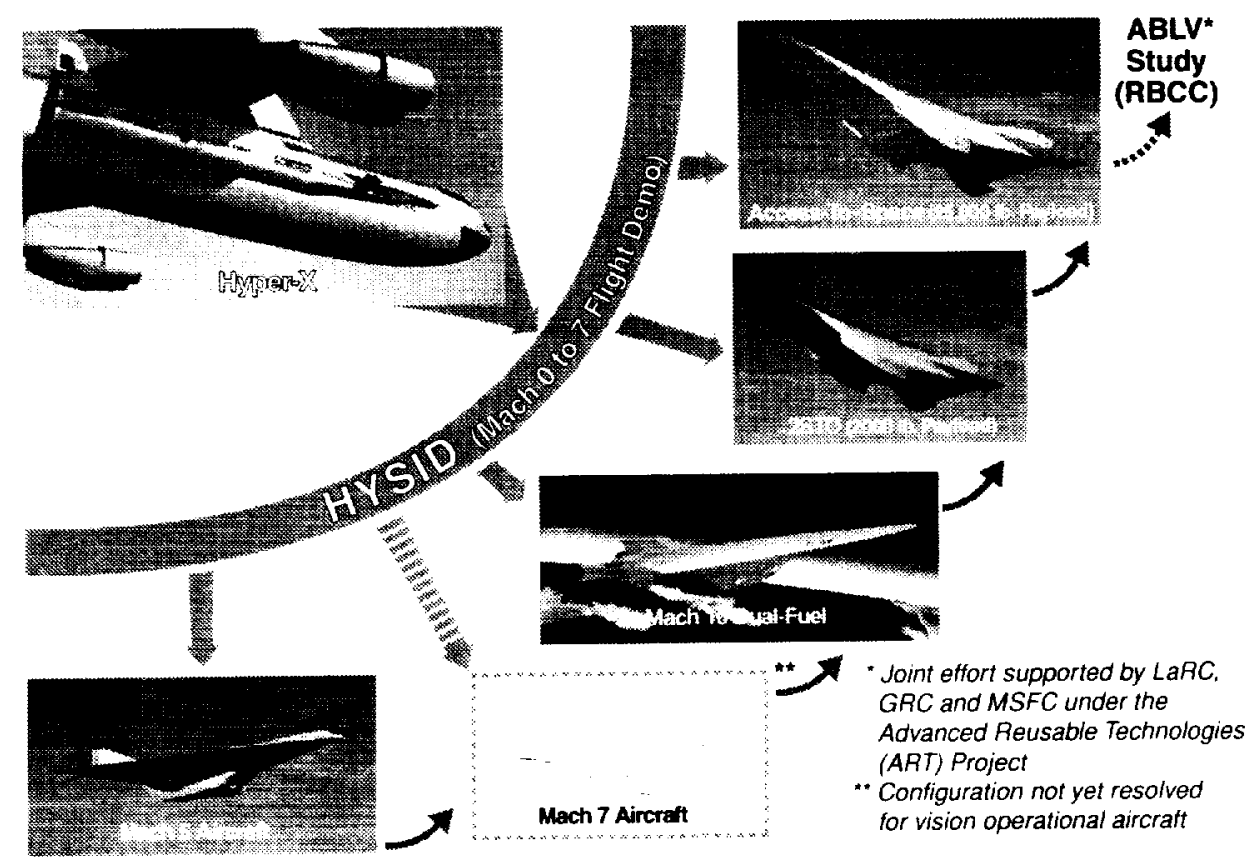

Figure 20. Hyper-X legacy...back to the future. 
The big picture here is that for unassisted horizontal takeoff, horizontal landing hypersonic vehicles with reasonably challenging missions including airplanes. dual role (pop-up/cruise) vehicles, and single-state-toorbit vehicles (and to a lesser extend TSTO vehicles) a synergy is appearing. The key technologies/systems, at least in a generic sense. appear to be converging across the matrix as indicated in figure 21 .

The configuration space is lifting-body except for perhaps endothermically-fueled Global Reach airplanes where the lift afforded by waveriders may prevail. The low-speed engine system is turbine or PDE's that don 't require LOX. The structures architecture is cold integral graphite epoxy except for perhaps non-cryogen fueled airplanes where hot integral architectures may have a role.

\footnotetext{
- Lifting Body Configuration

- Underslung over/under (two-duct) engine integration*

- AceTR/RTBE or PDE low-speed (over) propulsion system*

- Dual-Mode Scramjet high-speed (under) propulsion system with rocket ejection and/or tail rockets for SSTO and POp-up*

- Actively-cooled engine structural architecture

- Cold integral tank (Gr/Ep) airframe structural architecture with mechanically fastened insulation/TPS

- Endothermic, dual or all-hydrogen $\left(\mathrm{TPH}_{2}\right)$ tuel...to examine $\mathrm{LH}_{2}$ in FY2000

- Single duct, ABCC would also be viable for TSTO including Pop-up tor current architectures at predicted levels of performance, assuming functionality
}

Figure 21. Convergence/synergy in hypersonic airbreathing vehicle matrix (for unassisted HTHL systems).

\section{REFERENCES}

1. Hunt, J.L.; Lockwood, M.K.; Petley, D.H.; and Pegg, R.J.: Hypersonic Airbreathing Vehicle Visions and Enhancing Technologies. Space Technology and Applications International Forum. AIP Conference Proceedings 387. Albuquerque, NM, 1997.

2. Rausch, V.L.; McClinton, C.R.; and Crawford, J.L.: Hyper-X: Flight Validation of Hypersonic Airbreathing Technology. ISABE 97-7024.

3. Hunt, J.L.; and Couch. L.M.: Beyond Hyper-X. ASCE Space î8, Albuquerque, NM, A pril 26-30, 1998.

4. Pegg, R.J.; Hunt. J.L.; Petley, D.H.: Burkardt, L.; Stevens, D.R.; Moses, P.L.; Pinckney, S.Z.; Kabis. H.Z.; Spoth. K.A.; Dziedzic, W.M.: Kreis, R.I.: Martin. J.G.; and Barnhart, P.J.: Design of a Hypersonic Waverider-Derived Airplane. AIAA 93-0401.

5. Hunt. J.L.: and Eiswirth. E.A.: NASA's Dual-Fuel Airbreathing Hypersonic Vehicle Study. AIAA 96-4591.
6. Bogar, T.J.; Eiswirth, E.A.: Couch, L.M.; Hunt, J.L.; and McClinton, C.R.: Conceptual Design of a Mach 10, Global Reach Reconnaissance Aircraft. AIAA 96-2894.

7. Hunt. J.L.; Laruelle, G.; and Wagner, A.: Systems Challenges for Hypersonic Vehicles. AGARD Paper C.37, Ecole Polytechnique Palaiseau, Paris, France, 1997.

8. Saeks, R.: Cox. C.J.; and Pap, R.M.: LoFLYTE"!: A Neurocontrols Testbed. AIAA 97-0085.

9. Takashima, N.: L ewis. M.J.: Lockwood, M.K.; Bogar, T.: and Johnson, D.: Waverider Configuration Development for the Dual Fuel Vehicle. AIAA 96-4593.

10. Hunt, James L.; Rausch, Vincent L.: Airbreathing Hypersonic Systems Focus at NASA Langley Research Center. AIAA 98-16+1.

11. Access to Space Study: Summary Report: Office of Space Systems Development. NASA Headquarters, Jan. 1994

12. Bekey, I.: Powell, R.; and Austin, R.: NASA Studies Access to Space. Aerospace America, May 1994.

13. Hunt, J. L.: Airbreathing/Rocket Single-Stage-toOrbit Design Matrix. AIAA 95-6011.

14. Kothari, A.P.: Tarpley, C. et al.: Hypersonic Vehicle Design Using Inward Turning Flow fields. AIAA 96-25.52.

15. Keirsey. J.L.: A Study of the Aerodynamics of Scramjet Engine Inlets. The Johns Hopkins University Applied Physics Laboratory. TG-732. Sep. 1965.

16. Jackson, L.R.: An Accelerator Airplane Concept for Single-Stage-to-Orbit Flight. NASA TM 101563. Sept. 1989.

17. Hawkins, R.W.: and Richardson, P.F.: Design and Off-Design Performance Analysis of a Maximum Compression/ Minimum Drag Hypersonic Forebody. AIAA 91-3179.

18. Balepin. V.; Cozzog, P.; Marta, M.; and Vanderkerchhove: Assessment of SSTO Performance with In-Flight LOX Collection. AIAA 95-6047.

19. Bussing. R.R.A.: and Pappus, G.: An Introduction to Pulse Detonation Engines. AIAA 94-0263.

20. Gregory, T.; Bowles, J.; and Ardema, M.: Two Stage to Orbit Airbreathing and Rocket System for Low Risk, Affordable Access to Space. SAE 941 168.

21. Yi, A.C.: Reusable SSTO/TSTO Launch System Using Air Liquefaction Enrichment System (ALES Propulsion). NASA CR 191156. Volumes 1-5. June 1993.

22. Lockwood, M.K.: Hunt, J.L.; Kabis, H.Z.; Moses. P.L.; Pao, J.L.: Yarrington, P.W.: and Collier. C.: Design and Analysis of Two-Stage-to-Orbit Airbreathing Hypersonic Vehicle Concept. AIAA 96-2890.

23. Scuderi, G.F.. Orton, G.F., and Hunt, J.L.: Mach 10 Cruise/Space Access Vehicle Definition. AIAA $98-1584$. 
H 